\title{
Doing the Dirty Work: Measuring and Optimizing Resident Workload
}

\author{
Kathlyn E. Fletcher, $M D, M A^{7}$, Darcy A. Reed, $M D, M P H^{2}$, and Vineet M. Arora, MD, $M A^{3}$ \\ 'Department of Medicine, Milwaukee VAMC/Medical College of Wisconsin, Milwaukee, WI, USA; ${ }^{2}$ Department of Medicine, Mayo Clinic \\ College of Medicine, Rochester, MN, USA; ${ }^{3}$ Department of Medicine, University of Chicago, Pritzker School of Medicine, Chicago, IL, USA.
}

$\mathrm{J}$ Gen Intern Med 26(1):8-9

DOI: $10.1007 / \mathrm{s} 11606-010-1558-8$

(c) Society of General Internal Medicine 2010

$\mathrm{T}$ he importance of patient care in the development of future physicians has been recognized since well before Osler's time. Indeed, patient care experiences are the cornerstone of undergraduate and graduate medical education. While the purpose of residency training is to cultivate competent physicians primarily through direct patient care experiences, the optimal level of clinical work necessary to ensure resident learning and quality of care has not been well defined.

In this issue of the Journal of General Internal Medicine, Coit and colleagues consider whether reducing resident workload improves quality of patient care. ${ }^{1}$ The investigators implemented an experimental inpatient medicine rotation to reduce residents' workload at a community hospital. The intervention teams were comprised of three interns and two upper level residents, and the control teams consisted of two interns and one upper level resident. In addition, the intervention teams took call every sixth night and were limited to five admissions per resident, while the control teams were on call every fourth night and could admit up to twelve patients. Both teams were in compliance with ACGME duty hour standards.

The outcome of interest in this study was the quality of residents' discharge summaries, as measured by an instrument based on Joint Commission standards. The investigators demonstrated significant improvement in the quality of discharge summaries prepared by the intervention teams compared to those prepared by the control teams. Of note, certain aspects of discharge summaries were inadequately completed by residents in both groups, highlighting the need for further innovations to enhance the quality of discharge summaries.

Although educationally desirable, this intervention was not without significant cost. The service redesign required $66 \%$ more residents to take care of fewer patients. Because this may not be a feasible solution for many internal medicine residency programs, it is important to clarify the mechanism by which

"The student begins with the patient, continues with the patient, and ends his studies with the patient, using books and lectures as tools, as means to an end." -William Osler

Published online December 9, 2010 the improvements occurred and to demonstrate the generalizability of the findings. Were discharge summaries improved because of fewer patients? Less scut work? More support from nurses? Better interactions with attending physicians? Higher morale? Coit et al. postulated that increased time for reflection, fewer interruptions, and greater interaction with faculty may explain the observed differences in discharge summary quality. ${ }^{1}$ However, further study is needed to establish generalizability and to determine the feasibility of implementing similar interventions across residency programs of diverse size and resources.

An underlying assumption in the study by Coit and colleagues is that patient census is a good proxy for workload. Indeed, the Internal Medicine Residency Review Committee approximates workload using patient census by setting census caps for teaching services. Prior studies have shown that a higher patient census is associated with increased patient mortality and less time for educational activities on internal medicine services. ${ }^{2,3}$ However, additional measures of workload are needed to fully understand the impact of workload on important clinical and educational outcomes. Haney et al. modeled the number of admissions conducted by interns and residents as a measure of workload, and examined the relationship between admission volume and learning. ${ }^{4}$ In their study, the number of admissions associated with optimal learning for interns during an on-call shift was significantly fewer than the number needed to maximize learning for second and third year residents. ${ }^{4}$ These findings suggest that workload may have differential effects based on the level of experience of residents.

While patient census is frequently used as a proxy for resident workload, it is likely a crude approximation for several reasons. First, it does not account for patient complexity. One unstable patient with multiple medical problems may require more work and attention than two or three stable patients. Recognizing this, the Association of Program Directors of Internal Medicine developed a workload measure that incorporates patient illness severity. ${ }^{5}$ Second, measuring patient census alone does not adequately capture all of the work associated with a patient's entire length of stay including admission, discharge, and the intervening hospital days. ${ }^{6}$ Third, work-related stress must be considered. For example, interruptions (such as pages and emails), relationships among multi-disciplinary team members, and other environmental factors (including proximity of patients to the care team, efficiency of access to medical records and clinical services, as well as safety of the physical environment) can all contribute to workload. Finally, the 
various tasks that residents perform require different amounts of work; therefore specific tasks differentially contribute to a resident's overall workload. In studies of operating room workload, investigators have calculated a workload index for specific tasks by multiplying the amount of time spent on tasks by a factor that takes into account the relative difficulty of the task. ${ }^{7}$

Measuring workload by patient census or by individual patient also does not take into account the numerous ancillary tasks associated with clinical care that often fall to the resident. Time motion studies that have assessed type of work residents do demonstrate that as much as one-third of residents' time is spent in activities of marginal educational value, such as test ordering, tracking down results, and ancillary tasks (phlebotomy or transportation) that could be done by lesser trained professionals. ${ }^{8}$ Documentation requirements also place a heavy burden on residents, ${ }^{9}$ and although Coit and colleagues present a compelling argument for the value of discharge summaries in residents' education, ${ }^{1}$ other documentation activities may not enhance learning. These studies highlight the need to consider the scope and educational value of residents' work in interventions to improve residency education. This is even more important in light of the new 2011 resident duty hour restrictions. ${ }^{10}$ Limiting resident work hours, without examining appropriate workload and scope of work, may result in increased work intensity and undermine any potential benefits of working fewer hours.

As the medical profession embarks upon widespread changes in graduate medical education, the study by Coit et al. is an important first step toward understanding the relationship between workload and quality of care. However to ensure patient safety and resident education in today's internal medicine residencies, the 'dirty work' of measuring and optimizing resident workload still needs to be done.
Corresponding Author: Kathlyn E. Fletcher, MD, MA; Department of Medicine, Milwaukee VAMC/PC Division, 5000 W. National Ave., Milwaukee, WI, USA (e-mail: KFletche@mcw.edu).

\section{REFERENCES}

1. Coit MH, Katz JT, McMahon GT. The effect of workload reduction on the quality of residents' discharge summaries. J Gen Intern Med. 2010; XXXXXXX.

2. Ong M, Bostrom A, Vidyarthi A, McCulloch C, Auerbach A. House staff team workload and organization effects on patient outcomes in an academic general internal medicine inpatient service. Arch Intern Med. 2007; 167(1):47-52.

3. Arora VM, Georgitis E, Siddique J, Vekhter B, Woodruff JN, Humphrey HJ, Meltzer DO. Association of workload of on-call medical interns with on-call sleep duration, shift duration, and participation in educational activities. JAMA. 2008;300(10):1146-53.

4. Haney EM, Nicolaidis C, Hunter A, Chan BK, Cooney TG, Bowen JL. Relationship between resident workload and self-perceived learning on inpatient medicine wards: a longitudinal study. BMC Med Educ. 2006;6:35.

5. Bellini LM, Katz JT, Fried ED, Tulsky AA, Yadavali G, Pindiprolu S, Nielsen CD. Beyond duty hour reform: redefining the learning environment. APDIM Learning Environment Task Force. 2009. Available at: http://www.im.org/PolicyAndAdvocacy/PolicyIssues/Research/PSI/ Documents/09-06-04\%20Beyond\%20Duty\%20Hour\%20Reform\%2OFI NAL\%20Report.pdf. Accessed October 13, 2010.

6. Dellit TH, Armas-Loughran B, Bosl GJ, Sepkowitz KA, Thaler H, Blaskovich J. A method for assessing house staff workload as a function of length of stay. JAMA. 2001;286(9):1023-4.

7. Weinger MB, Reddy SB, Slagle JM. Multiple measures of anesthesia workload during teaching and nonteaching cases. Anesth Analg. 2004;98(5): 1419-25.

8. Boex JR, Leahy PJ. Understanding residents' work: moving beyond counting hours to assessing educational value. Acad Med. 2003;78 (9):939-44

9. Oxentenko AS, West CP, Popkave C, Weinberger SE, Kolars JC. Time spent on clinical documentation: a survey of internal medicine residents and program directors. Arch Intern Med. 2010;170(4):377-80.

10. Accreditation Council for Graduate Medical Education Approved Standards. Available at: http://acgme-2010standards.org/. Accessed October 12,2010 